\title{
New insights into the association between lameness, behavior, and performance in Simmental cows
}

\author{
Katharina Grimm, ${ }^{1 *}$ Bernhard Haidn, ${ }^{1}$ Michael Erhard, ${ }^{2}$ Marlene Tremblay, ${ }^{3}$ and Dörte Döpfer ${ }^{3}$ \\ ${ }_{1}^{1}$ Institute for Agricultural Engineering and Animal Husbandry, Bavarian State Research Center for Agriculture, Munich 85586, Germany \\ ${ }^{2}$ Chair of Animal Welfare, Animal Behavior, Animal Hygiene und Animal Husbandry, Department of Veterinary Sciences, \\ Faculty of Veterinary Medicine, Ludwig-Maximilians-University, Munich 80539, Germany \\ ${ }^{3}$ Food Animal Production Medicine Section, School of Veterinary Medicine, University of Wisconsin, Madison 53706
}

\section{ABSTRACT}

In a herd of 100 milking Simmental cows, data of performance and behavior parameters were collected automatically with different systems such as pedometers, an automatic milking system, and automatic weighing troughs for $1 \mathrm{yr}$. Performance measures were several milking-related parameters, live weight, as well as feed intake. Behavior-associated measures were feeding behavior (e.g. feeding duration, number of visits to the trough, and feeding pace) as well as activity such as lying duration, number of lying bouts, and overall activity. In the same time, lameness status of every cow was assessed with weekly locomotion scoring. According to the score animals were then classified lame (score 4 or 5 ) or nonlame (score 1, 2, or 3). From these data in total, 25 parameters summarized to daily values were evaluated for their ability to determine the lameness status of a cow. Data were analyzed with a regularized regression method called elastic net with the outcome lame or nonlame. The final model had a high prediction accuracy with an area under the curve of 0.91 $[95 \%$ confidence interval $(\mathrm{CI})=0.88-0.94]$. Specificity was $0.81(95 \% \mathrm{CI}=0.73-0.85)$ and sensitivity was 0.94 $(95 \% \mathrm{CI}=0.88-1.00)$. The most important factors associated with a cow being lame were number of meals, average feed intake per meal, and average duration of a meal. Lame cows fed in fewer and shorter meals with a decreased intake per meal. Milk yield and lying-behavior-associated parameters were relevant in the model, too, but only as parts of interaction terms demonstrating their strong dependence on other factors. A higher milk yield only resulted in higher risk of being lame if feed intake was decreased. The same accounts for lying duration: only if lying time was below the $50 \%$ quantile did an increased milk yield result in a higher risk of being lame. The association of lameness and daily lying

Received May 9, 2018.

Accepted November 10, 2018.

*Corresponding author: grimm.k@hotmail.com duration was influenced by daily feeding duration and feeding duration at daytime. The results of the study give deeper insights on how the association between behavior and performance parameters and lameness is influenced by intrinsic factors in particular and that many of these have to be considered when trying to predict lameness based on such data. The findings lead to a better understanding why, for instance, lying duration or milk yield seem to be highly correlated with lameness in cows but still have not been overly useful as parameters in other lameness detection models.

Key words: lameness, behavior, performance, dairy cow, automatic lameness detection

\section{INTRODUCTION}

Lameness in cattle is one of the major issues in modern dairy production and one of the main causes for culling. After udder health and fertility, hoof diseases were the third most important reason for culling in Bavaria, Germany, in 2014 (Landeskuratorium der Erzeugerringe für tierische Veredelung in Bayern e. V., 2015) and were in second place in Saxony, Germany, in first-lactating heifers in 2008 (Brade et al., 2008). In different studies from all over the world, lameness prevalence in dairy cattle ranges from one-third to more than one-half of the herd (Dippel et al., 2009; Barker et al., 2010; von Keyserlingk et al., 2012).

Acute and chronic lameness account for significant economic loss with cases costing from $€ 130$ up to $€ 600$. These losses are mainly due to the cost of treatment, as well as the economic damage caused by reduced performance in lame animals (Rademacher et al., 2004; Souza et al., 2006; Ozswari et al., 2007). Also, apart from the financial consequences of lameness, hoof diseases can cause severe pain. Hence, it is important to detect lameness as early as possible because the sooner the causing lesion is treated in its course of development, the less it affects the well-being and performance of the animal and the shorter is the duration of the recovery (Laven et al., 2008; Leach et al., 2012). Higher surveil- 
lance rates may ensure an early detection of lameness, but in fact, farmers underestimate the actual lameness prevalence in their herd. In a study conducted in Czech Republic (Šárová et al., 2011), farmers only recognized a fifth of the lameness cases. Whay et al. (2002) found that farmers in Great Britain on average only recognized a quarter of their lame animals.

Thus, finding ways to automatically detect lameness could be very beneficial to animal welfare and reduce economic loss due to lameness in dairy cows. More and more processes in dairy production are currently being automated using individualized animal data. Automatic milking robots measure milking parameters such as milk yield (MY), milk flow, milking duration, and so on. Accelerometers used for heat detection no longer only measure activity but also lying and feeding behavior to assess irregular changes in the data as an indicator of health issues. As a consequence, a lot of automatically recorded performance and behavior data are collected that are not yet taken advantage of exhaustively. Numerous studies have proven associations between lameness and the many parameters measured by automatic sensors, revealing the high potential of detecting lameness based on the analysis of automatically measured behavior and performance data. The number of visits to the feed bunk, for instance, has been shown to decrease significantly in lame animals (Bach et al., 2007; Kramer et al., 2009; Miekley et al., 2013; Miguel-Pacheco et al., 2014; Thorup et al., 2016). An increasing lying time per day can also be an indicator of lameness in dairy cows (Ito et al., 2010; Blackie et al., 2011; Calderon and Cook, 2011; Thorup et al., 2015; Westin et al., 2016).

Calculation models for lameness detection consisting of different combinations of MY, activity, live weight (LW), rumination variables, lying behavior, concentrate intake, and feeding behavior have led to moderate to high predictive accuracy (Kramer et al., 2009; de Mol et al., 2013; Kamphuis et al., 2013; Miekley et al., 2013; Garcia et al., 2014; Van Hertem et al., 2016). The model with the highest accuracy (de Mol et al., 2013) achieved a sensitivity of $86 \%$ and a specificity of $89 \%$ using MY, activity, lying behavior, and concentrate intake. Still, the associations between lameness, individual and environmental factors, and behavior and performance parameters have not yet been evaluated sufficiently. The interaction between behavioral and performance measures with regard to lameness has not been the subject of current research. Additionally, all of the studies were conducted with pure dairy breeds such as Holstein. To our knowledge, no research has analyzed these associations in a dual-purpose breed such as Simmental. Thus, the aim of our study was to investigate the interaction between behavioral and performance measures with regard to lameness in Simmental cows.

\section{MATERIALS AND METHODS}

In the dairy herd of the Bavarian State Research Center for Agriculture, Munich, Germany, performance and behavior parameters were recorded continuously from March 2014 to May 2015.

\section{Study Herd and Housing}

Throughout the trial, the study herd consisted of 73 Simmental and 2 Brown Swiss cows of which a maximum of 65 cows were lactating at the same time. The average MY per year and cow was $8,210 \mathrm{~kg}$ and the average parity was 2.37 (minimum $=1$, maximum $=9$, $\mathrm{SD}=1.5$ ). Due to restocking, a total of 100 cows were observed in the trial.

During lactation cows were housed in a freestall barn with half deep bedding and half rubber mat cubicles and with slatted floors with an additional rubber top in the lying area. They were milked with an automatic milking robot (DeLaval VMS 2009, Tumba, Sweden). Dry cows were housed in a separate freestall barn with a solid floor and rubber mat cubicles. The animal:cubicle ratio was 1:1 in both of the barns. During the dry-off period cows had access to an open-air area throughout the whole year and to pasture from May to September. For calving the cows were taken to a $25-\mathrm{m}^{2}$ calving pen with deep straw bedding. If an animal was suspected by the farm staff to be ill, it was separated and carefully examined by a veterinarian. Cows were fed a partial mixed ration once a day through weighing troughs and were fed up to $6 \mathrm{~kg}$ of concentrate in the automatic milking system and additionally through automatic concentrate feeders depending on their individual MY. During the study period, a feeding trial was conducted on the farm, so the feeding regimen was different from March 2014 to November 2014 (feeding phase 1) to the time from November 2014 to May 2015 (feeding phase 2). In feeding phase 1 , all cows were fed the same roughage of $6.9 \mathrm{MJ}$ of $\mathrm{NE}_{\mathrm{L}}$ per $\mathrm{kg}$ of $\mathrm{DM}$ plus $200 \mathrm{~g}$ of concentrate per $\mathrm{kg}$ of ECM; feeding phase 2 had 2 different groups of 2 different energy levels in the feed: 6.1 MJ of $\mathrm{NE}_{\mathrm{L}} / \mathrm{kg}$ of DM plus $250 \mathrm{~g}$ of concentrate per $\mathrm{kg}$ of ECM and $6.5 \mathrm{MJ}$ of $\mathrm{NE}_{\mathrm{L}} / \mathrm{kg}$ of DM plus $150 \mathrm{~g}$ of concentrate per $\mathrm{kg}$ of ECM.

\section{Data Collection}

Because the sensors of the trial were only installed in the barn for lactating cows, data were only collected during lactation. 
Determination of Lameness. Lameness was scored with a 5-point locomotion score (LMS) modified according to Sprecher et al. (1997) by the same trained observer fortnightly in the first $3 \mathrm{mo}$, weekly during the rest of the study period. The score was modified in a way that every animal with an obvious gait irregularity ["short-striding on one or more limbs" (Sprecher et al., 1997)] was defined as score 4 as opposed to the original scale where a cow with this characteristic would still be score 3, which was found to be hard to differentiate from the definition of score 4 ["the cow favors one or more limbs/feet" (Sprecher et al., 1997)]. Animals with an "arched-back posture ... evident both while standing and walking" (Sprecher et al., 1997) but without signs of gait irregularity were assigned score 3 . When a cow only had an arched back while standing, she was assigned score 2 .

In total, 1,888 LMS were recorded and after data were cleansed as described later, 1,622 (86\%) LMS of 89 cows were left for the analysis. The frequency of different LMS is shown in Table 1.

All animals with a LMS higher than 3 or those that were detected to be lame by the farm staff were treated by the same veterinarian immediately and rechecked until complete recovery from the lesion causing the lameness.

To assess intra-observer reliability, the herd was scored by the observer who scored throughout the study period for 2 consecutive locomotion scorings within 1 h. After applying the binary classification of lame and nonlame animals used in the analysis, Cohen's kappa (Cohen, 1960) was calculated. Cohen's kappa corrects the relative agreement by random agreement.

Automatic Sensors. Every animal was equipped with a radio-frequency identification transponder attached to the ear, which made it possible to collect individualized data from all sensors installed in the barn. These data were then merged in a PostgreSQL database
(The PostgreSQL Global Development Group, https:// www.postgresql.org).

Milk yield was measured by the milking robot, which had a built-in scale to measure LW at every milking. Feeding data were collected with 36 automatic weighing troughs constructed by engineers from our institute (Fröhlich et al., 2005) recording animal ID, time, and weight of the feed in the trough at the beginning and end of the visit. A new visit was defined as every registration of these data after a pause of more than $10 \mathrm{~s}$. Track a Cow pedometers (ENGS Systems, Rosh Pina, Israel) attached to the forelimb of every cow measured activity as a dimensionless index representing the amount of leg movement, registered if a cow was lying or standing every $8 \mathrm{~s}$ and then summarized as lying time and the number of lying bouts per hour.

\section{Data Processing}

All sensor data were merged in a PostgreSQL database and summarized into daily values. Based on the data from the milking robot daily values for MY, number of milkings, maximum time between 2 milkings, or milking interval (MI) as well as LW were computed. Milk yield was attributed proportionally to each day depending on the time the milking took place at the particular day. If a cow milked at $1800 \mathrm{~h}$ and again at $0400 \mathrm{~h}$ at the following day, meaning a $10 \mathrm{~h}$ difference, $60 \%$ of the MY was assigned to the first day and $40 \%$ was assigned to the second day. Maximum duration between 2 milkings was defined as the maximum duration between a milking at the current day and the next or previous milking. Live weight data from every visit to the automatic milking system were summarized to a daily median.

For every animal, daily feed intake (FI) and feeding duration $(\mathbf{F D})$, average feeding pace $(\mathbf{F P})$, calculated by FI divided by FD, as well as number of the visits to

Table 1. Frequencies of different locomotion scores

\begin{tabular}{lcrrrrr}
\hline & \multicolumn{7}{c}{ Number of evaluations by LMS } \\
\cline { 2 - 6 } Animal ID & 1 & 2 & 3 & 4 & 5 & Total \\
\hline 296 & 1 & 1 & 0 & 0 & 0 & 2 \\
299 & 1 & 13 & 8 & 2 & 0 & 24 \\
370 & 3 & 10 & 5 & 1 & 1 & 20 \\
Total & 1,044 & 426 & 110 & 40 & 2 & 1,622 \\
Median & 11.5 & 3 & 0 & 0 & 0 & 20.5 \\
Minimum & 0 & 0 & 0 & 0 & 0 & 1 \\
Maximum & 28 & 24 & 15 & 6 & 1 & 29 \\
First quartile & 4 & 1 & 0 & 0 & 0 & 13 \\
Third quartile & 19 & 8 & 1 & 0 & 0 & 24 \\
\hline
\end{tabular}

${ }^{1} \mathrm{LMS}=$ locomotion score. 
the trough (VN), average feed intake per visit (FIV), and average feeding duration per visit (FDV), were calculated from the weighing trough data. Additionally, a meal criterion was defined according to a trial (Oberschätzl-Kopp, 2018) conducted in a barn and Simmental herd of a very similar structure as the one in our institute where an individual meal criterion for every cow was calculated with a method after Tolkamp et al. (2000) modified according to Yeates et al. (2001, 2002). The median meal criterion length of $20 \mathrm{~min}$ of the cows in that barn was then used for our calculations, to summarize all visits with a pause shorter than 20 min between them into one single meal.

All variables calculated for the visits to the trough were also calculated for meals: number of meals (MN), average feed intake per meal (FIM), and average feeding duration per meal (FDM).

The hourly summarized pedometer data for activity (AC), lying duration (LD), and number of lying bouts (LBN) were accumulated to daily values, and the average duration of a lying bout (LDB) was computed by dividing the daily lying time by the number of lying bouts.

As in the study of Van Hertem et al. (2013), the relation between daytime activity and nighttime activity proved to be a relevant indicator of lameness; a daytime ratio was calculated, which was defined by the measure's value for the daytime ( 0500 to $2200 \mathrm{~h}$ ) divided by the value of the sum for the whole day, respectively, for the measures feeding duration (FDD), number of visits to the trough (VND), number of meals (MND), lying duration (LDD), number of lying bouts (LBND), and activity (ACD).

Finally, the results of the lameness scoring, information about parity, and DIM were added to the data set. Days in milk were categorized in 4 categories $(<61$ $\mathrm{d}=0,61-120 \mathrm{~d}=1,121-270 \mathrm{~d}=2$, and $>270 \mathrm{~d}=$ $3)$. Parity $(\mathbf{P})$ was categorized in 3 groups (parity $1=$ 1 , parity $=2=2$, parity $\geq 3=3$ ). The date variable was categorized by season $(\mathbf{S}$; winter $=$ December 1 to February 28, spring = March 1 to May 31, summer $=$ June 1 to August 31, and fall $=$ September 1 to November 30). The described change in feeding (CF) was categorized by feeding phase 1 and feeding phase 2 .

Data were cleansed to exclude missing or faulty values. In particular these were data for every cow during the dry-off period, the days when it was in the separation booth that had no weighing troughs or cubicles, days when a cow was treated, and days when the lying data were implausible such as lying times less than 30 min per day or when the following measures were of value zero: MY, FI, FP, FIV, FIM, LBN, LDD, and ACD. After deleting every data set with missing or faulty values, 26,844 (78.39\%) of the former 34,246 daily data sets were left for the analysis.

The MY, MI, FI, FD, FP, FDM, VN, FIV, FDV, FIM, LD, LDB, and AC were transformed by taking the natural logarithm to achieve normally distributed data. For the purpose of comparability, all variables were centered (the mean of all the variable's values was subtracted from each value) and scaled (every value of the variable was divided by the standard deviation of the variable).

\section{Statistical Analysis}

All statistical calculations were carried out with the language and environment for statistical computing R (R Core Team, 2015). The outcome of interest was lameness status (lame or nonlame). A cow was defined as lame when her LMS was higher than 3. Cows with score 3 or lower were considered nonlame. Locomotion scoring and treatment of hoof lesions, if required, implied a change in normal daily routine of the cows, and thus, their behavior. Because a cow being lame already on the day before it was scored was highly plausible, only data from the day before the scoring were used in the analysis. First, univariate analysis was conducted for every variable with the lameness status as a binary outcome in contingency tables to calculate the odds ratio. The variables with no statistically significant association with the outcome were not used for further analysis. To reduce collinearity in the model, Pearson correlation coefficients between all variables were calculated in pairs. In those pairs with a correlation coefficient $r>0.7$, the one with less strong association with the outcome "lame" or the one with fewer available data was omitted from further analysis. Table 2 summarizes the analyzed parameters, if they were finally used for model formulation, and which ones were measured directly or calculated from those parameters measured.

The cleansed data set consisted of 33 cases (lame) and 1,019 controls (nonlame) and is a case of very unbalanced data. That is why synthetic minority oversampling technique (SMOTE; Chawla et al., 2002) was performed. The SMOTE is a combination of oversampling the minority class and under-sampling the majority class. Minority class data (in our study: data of lame cows) are synthesized by creating new data records based on the vectors of the $\mathrm{k}$ nearest neighbors from the same class (in the case of this study, $\mathrm{k}=5$ ). The $\mathrm{k}$ nearest neighbors are the number $\mathrm{k}$ of those data points whose values are nearest the considered data point. Down-sampling of the majority class is done by random sampling. Applying SMOTE resulted in an 
almost 1:1 ratio with 528 cases and 544 controls in the data.

Model Formulation and Validation. After balancing the data, in a first step, a forward stepwise logistic regression with the outcome lame or nonlame was performed with all the remaining variables and every possible interaction term between all of them to determine relevant interaction terms. The interaction terms were added to the full model containing all the single parameters stepwise and were retained if significant at $P \leq 0.05$. Interaction terms that had remained in the forward step regression model were included for further analysis. Second, the data were analyzed with a regularized regression method called elastic net (ENET; Zou and Hastie, 2005); ENET combines the 2 regularization methods: ridge regression (Hoerl and Kennard, 1970) and lasso (Tibshirani, 1996). Both methods perform continuous coefficient shrinkage, which decreases the variance of the model, but only lasso provides variable selection, which improves interpretability. Additionally, ridge regression stabilizes the regularization, implements a grouping effect, and is not limited by the number of possible predictors as lasso is (Liu and Li, 2017). That is why ENET, as a combination of both of these methods, is particularly useful in data sets with many predictors and when dealing with multicollinearity in the data (Zou and Hastie, 2005) as was found in the analysis beforehand. It contains 2 tuning parameters $\lambda \in[0, \infty]$ and $\alpha \in[0,1] . \lambda$ primarily determines the shrinkage of the coefficients and variable selection. If it is zero, coefficients are equal to least squares estimates, and as it increases, the coefficients are shrunk to almost zero. $\alpha$ determines the weighting between lasso and ridge regression. In this study, they were determined by 10 -fold cross-validation in 2 steps. First, to establish the best value of $\alpha$, a 10-fold cross-validated ENET was performed twice with each of the following values for $\alpha: 0,0.01,0.05,0.1,0.15,0.2,0.3,0.4,0.5,0.6,0.7,0.8$, $0.85,0.9,0.95,0.99$, and 1 . The mean absolute error (MAE) of every model with the different $\alpha$-values and the average of the 2 results per $\alpha$-value were calculated, respectively. Then ENET was applied to the data 10fold cross-validated using the $\alpha$-value that had resulted in the lowest average of MAE to determine the $\lambda$ with the lowest MAE and the coefficients in the model.

After the application of ENET, the advanced ENET beta (Liu and $\mathrm{Li}, 2017$ ) was applied to the final model to achieve an even sparser and therefore more interpretable and stable model. ENET beta applies ENET to the data and performs further variable selection by using hypothesis testing. Therefore, first, only the predictor with the largest magnitude from the ENET

Table 2. Transformation and use of the variables for statistical modeling

\begin{tabular}{|c|c|c|c|}
\hline Variable & Abbreviation & $\log ^{1}$ & $\begin{array}{l}\text { Measured (M) or } \\
\text { calculated (C) }\end{array}$ \\
\hline Change of feed ${ }^{2}$ & $\mathrm{CF}^{2}$ & No & - \\
\hline Season $^{2}$ & $S^{2}$ & No & - \\
\hline Parity $^{2}$ & $\mathrm{P}^{2}$ & No & - \\
\hline $\mathrm{DIM}^{2}$ & $\mathrm{DIM}^{2}$ & No & - \\
\hline Milk yield ${ }^{2}$ & $\mathrm{MY}^{2}$ & Yes & M \\
\hline Milking interval $^{2}$ & $\mathrm{MI}^{2}$ & Yes & M \\
\hline Live weight & LW & No & M \\
\hline Feed intake $^{2}$ & $\mathrm{FI}^{2}$ & Yes & M \\
\hline Feeding duration ${ }^{2}$ & $\mathrm{FD}^{2}$ & Yes & M \\
\hline Feeding duration daytime ${ }^{2}$ & $\mathrm{FDD}^{2}$ & No & $\mathrm{C}$ \\
\hline Feeding pace & $\mathrm{FP}$ & Yes & $\mathrm{C}$ \\
\hline Number of meals ${ }^{2}$ & $\mathrm{MN}^{2}$ & No & $\mathrm{C}$ \\
\hline Number of meals daytime & MND & No & $\mathrm{C}$ \\
\hline Feeding duration per meal ${ }^{2}$ & $\mathrm{FDM}^{2}$ & Yes & $\mathrm{C}$ \\
\hline Feed intake per meal ${ }^{2}$ & FIM $^{2}$ & Yes & $\mathrm{C}$ \\
\hline Number of visits ${ }^{2}$ & $\mathrm{VN}^{2}$ & Yes & M \\
\hline Number of visits daytime & VND & No & $\mathrm{C}$ \\
\hline Feeding duration per visit & FDV & Yes & $\mathrm{C}$ \\
\hline Feed intake per visit & FIV & Yes & $\mathrm{C}$ \\
\hline Lying duration ${ }^{2}$ & $\mathrm{LD}^{2}$ & Yes & M \\
\hline Lying duration daytime $^{2}$ & $\mathrm{LDD}^{2}$ & No & $\mathrm{C}$ \\
\hline Number of lying bouts & $\mathrm{LBN}$ & No & M \\
\hline Number of lying bouts daytime ${ }^{2}$ & $\mathrm{LBND}^{2}$ & No & $\mathrm{C}$ \\
\hline Lying duration per bout ${ }^{2}$ & $\mathrm{LDB}^{2}$ & Yes & $\mathrm{C}$ \\
\hline Activity & $\mathrm{AC}$ & Yes & M \\
\hline Activity daytime & $\mathrm{ACD}$ & No & $\mathrm{C}$ \\
\hline
\end{tabular}


model is used to build a new model performing ENET with the same method that is used for the first ENET model. In the next step the predictor with the second largest magnitude is added to the model and ENET is performed again; third, the third largest predictor is added, and so on. This is done until every predictor is in the model. After that, the Brier score (BR) for each of the models is calculated and the minimum value $\mathrm{BR}_{\text {min }}$ of all the scores is determined. The model with the smallest number of predictors and with $\mathrm{BR}_{\min } / \mathrm{BR}$ $>0.9$ is chosen as the final model.

To determine sensitivity and specificity of the final model the receiver operating characteristic curve analysis was conducted on the basis of the data not subjected to SMOTE and subjected to SMOTE, respectively.

Analysis of the Parameters in the Model. Unlike in linear or logistic regression, in ENET the dimension of the coefficients in the model cannot directly be interpreted as the magnitude of association with the outcome of the parameters but can at most represent an approximation of it. Therefore, data were analyzed in a logistic regression with all the parameters that had remained in the final model. Finally, the magnitude and direction of the coefficients of the predictors could be interpreted as the magnitude and direction of the association they had with the outcome lame or nonlame. The more complex nature of the association between the outcome and the interaction terms was further analyzed by plotting the effect of one of the predictors in the interaction term on the outcome for the $5,10,25$, 50,75 , and $100 \%$ quantile values of the other predictor when all the other predictors in the model were kept at their mean.

\section{RESULTS}

\section{Intra-Rater Reliability}

Cohen's kappa, calculated as a measure of intra-rater reliability was $0.7(95 \% \mathrm{CI}=0.38-1.00)$ with a $95 \%$ agreement between the 2 scorings that were done by the same observer within $1 \mathrm{~h}$.

\section{Lameness Cases}

In total there were 33 lameness cases of 16 animals with $19(58 \%)$ cases of laminitis-caused lesions (double sole and white line disease). Four (12\%) lameness cases were caused by phlegmon, $3(9 \%)$ by sole ulcers, and $2(6 \%)$ were caused by acute digital dermatitis (DD). Five $(15 \%)$ cases were caused by other diseases like interdigital hyperplasia, interdigital dermatitis, and corkscrew claw. Twenty-six of these cases were new le- sions of animals that were nonlame previously for at least 3 consecutive scorings. Accordingly, the remaining 9 have been repeated scorings of one of these new cases. To address this problem of repeated cases in regression, a variable was introduced representing the number of times a case had been repeated. However, it had no influence on the predictive quality of the model either as a fixed or as a random effect throughout the applied steps of the analysis (results not shown) and was therefore excluded.

\section{Univariate Analysis}

Table 3 shows median, as well as the first and third quartile, of the analyzed parameters to demonstrate location scales of the data as well as their odds ratios for being lame. Almost all of the analyzed parameters were statistically significantly associated with each other and most of the analyzed behavioral parameters were statistically significantly associated with the outcome lame or nonlame when analyzing the odds ratio. For instance, cows with a higher than average duration of MI were 3.5 times more likely to be lame. When cows fed shorter than average they were 7.1 times more likely to be lame and cows with a higher than average FDD, meaning they fed primarily during daytime had a 2.58 times higher chance of being lame than those that fed also during nighttime. Presumably as a consequence of the shorter FD in lame cows, FP was higher in lame cows than in nonlame cows with a 4.5 times higher chance for being lame when FP was above average. But as expected, it correlated highly $(\mathrm{r}=0.77)$ with FD, which was therefore favored for further model formulation because of the greater relevance of the variable as its use does not require the expensive technique of weighing troughs. Lying behavior also changed in lame animals. For instance, a cow was 6.8 times more likely to be lame, when LDB was above average. It should be considered that there was very high intercorrelation between the single parameters, and taking the influence of other factors into account in a multivariate analysis could change the association described here.

Only performance measures and external parameters such as MY, LW, FI, S, and CF as well as DIM did not show any significant association. The FDV, AC, and ACD were the only behavioral parameters that were not statistically significantly associated with the lameness status.

\section{Multivariate Analysis}

Forward Stepwise Logistic Regression. The forward stepwise logistic regression resulted in the inclu- 
sion of the following interaction terms: $\mathrm{MY} \times \mathrm{FI}, \mathrm{CF} \times$ $\mathrm{S}, \mathrm{FDD} \times \mathrm{LDB}, \mathrm{FD} \times \mathrm{LDB}, \mathrm{FDM} \times \mathrm{CF}, \mathrm{MY} \times \mathrm{LD}$, and $\mathrm{FD} \times \mathrm{CF}$.

Elastic Net and Elastic Net Beta. After the determination of the relevant interaction terms ENET was applied to the complete model of the following form:

$$
\begin{gathered}
\text { outcome }(\text { lame or nonlame }) \sim \mathrm{MY}+\mathrm{MI}+\mathrm{FI} \\
+\mathrm{FD}+\mathrm{FDD}+\mathrm{MN}+\mathrm{FDM}+\mathrm{VN}+\mathrm{FIM}+\mathrm{LD} \\
+\mathrm{LDD}+\mathrm{LBND}+\mathrm{LDB}+\mathrm{DIM}+\mathrm{S}+\mathrm{CF}+\mathrm{P} \\
+\mathrm{MY} \times \mathrm{FI}+\mathrm{CF} \times \mathrm{S}+\mathrm{FDD} \times \mathrm{LDB}+\mathrm{FD} \times \mathrm{LDB} \\
+\mathrm{FDM} \times \mathrm{CF}+\mathrm{MY} \times \mathrm{LD}+\mathrm{FD} \times \mathrm{CF} .
\end{gathered}
$$

The model that included all of the 24 predictors, meaning that $\lambda$ was low, had the lowest MAE and was therefore used for further analysis. Applying ENET beta subsequently resulted in the exclusion of 6 more parameters: $\mathrm{FDM} \times \mathrm{CF}, \mathrm{LDD}, \mathrm{FD} \times \mathrm{CF}, \mathrm{DIM}, \mathrm{VN}$, $\mathrm{MI}$, and $\mathrm{P}$.

\section{Accuracy of the Final Model}

The final model reached an area under the curve of $0.94(95 \% \mathrm{CI}=0.93-0.95)$. Specificity was 0.83 $(95 \% \mathrm{CI}=0.78-0.88)$ and sensitivity was $0.92(95 \% \mathrm{CI}$ $=0.88-0.96)$. When the model was applied to the data set not subjected to SMOTE, results lay very close to those of the balanced data with an area under the curve of 0.91 (95\% CI $=0.88-0.94)$, a specificity of $0.81(95 \% \mathrm{CI}=0.73-0.85)$, and a sensitivity of 0.94 $(95 \% \mathrm{CI}=0.88-1.00)$.

\section{Analysis of the Parameters in the Model}

As mentioned before, the magnitude of the coefficients in the ENET beta model cannot be interpreted as a measure of the strength of association of the prevailing predictor, which is why a logistic regression was performed with the parameters that had remained in the ENET beta model for further analysis. In this logistic regression model, every parameter showed a statistically significant association with the outcome. Because

\begin{tabular}{|c|c|c|c|c|c|c|}
\hline Parameter $^{1}$ & Nonlame & Lame & OR lame & $P$-value & $95 \% \mathrm{CI}$ & $\mathrm{n}$ \\
\hline $\mathrm{CF}$ & - & - & 1.41 & 0.33 & $0.71-2.80$ & 1,613 \\
\hline S & - & - & 1.05 & 1.00 & $0.58-1.91$ & 1,613 \\
\hline $\mathrm{P}$ & $2(1 ; 3)$ & $3(2 ; 5)$ & 2.65 & 0.01 & $1.23-5.72$ & 1,613 \\
\hline DIM & $152(82 ; 231)$ & $180(65 ; 254)$ & 1.41 & 0.33 & $0.71-2.80$ & 1,613 \\
\hline MY & $23.3(18.7 ; 28.5)$ & $25.2(19.4 ; 30.6)$ & 0.64 & 0.17 & $0.36-1.16$ & 1,562 \\
\hline MI & $699.6(603.4 ; 797.6)$ & $779.7(713.9 ; 854.5)$ & 3.50 & 0.00 & $1.80-6.82$ & 1,608 \\
\hline LW & $794.3(716.6 ; 856.3)$ & $794.1(734.9 ; 840.8)$ & 1.13 & 0.77 & $0.63-2.05$ & 1,608 \\
\hline FI & $40.6(34.8 ; 46.6)$ & $40.3(32.1 ; 46.2)$ & 1.01 & 1.00 & $0.56-1.82$ & 1,611 \\
\hline FD & $173.4(132.4 ; 218.5)$ & $108.1(87.4 ; 151.0)$ & 0.14 & 0.00 & $0.06-0.30$ & 1,612 \\
\hline FDD & $0.85(0.76 ; 0.93)$ & $0.95(0.83 ; 1.00)$ & 2.58 & 0.00 & $1.39-4.81$ & 1,612 \\
\hline $\mathrm{FP}$ & $0.23(0.17 ; 0.33)$ & $0.36(0.27 ; 0.49)$ & 4.50 & 0.00 & $2.32-8.77$ & 1,611 \\
\hline $\mathrm{MN}$ & $6(5 ; 8)$ & $5(4 ; 6)$ & 0.34 & 0.00 & $0.17-0.67$ & 1,612 \\
\hline MND & $0.80(0.75 ; 0.88)$ & $0.83(0.80 ; 1.00)$ & 1.94 & 0.04 & $1.06-3.54$ & 1,612 \\
\hline FDM & $37.1(27.9 ; 47.5)$ & $29.4(21.8 ; 37.2)$ & 0.33 & 0.00 & $0.18-0.61$ & 1,612 \\
\hline FIM & $6.39(5.15 ; 7.94)$ & $7.72(5.79 ; 8.69)$ & 2.36 & 0.01 & $1.23-4.52$ & 1,611 \\
\hline VN & $41(30 ; 56)$ & $27(15 ; 32)$ & 0.15 & 0.00 & $0.07-0.34$ & 1,612 \\
\hline VND & $0.85(0.76 ; 0.93)$ & $0.96(0.83 ; 1.00)$ & 2.58 & 0.00 & $1.38-4.79$ & 1,612 \\
\hline FDV & $4.34(3.18 ; 5.72)$ & $4.88(3.24 ; 6.66)$ & 1.23 & 0.55 & $0.68-2.22$ & 1,612 \\
\hline FIV & $0.98(0.68 ; 1.36)$ & $1.61(1.24 ; 2.81)$ & 6.59 & 0.00 & $2.93-14.82$ & 1,611 \\
\hline LD & $708(611 ; 820)$ & $880(721 ; 1,046)$ & 3.98 & 0.00 & $1.71-925$ & 1,158 \\
\hline LDD & $0.60(0.54 ; 0.65)$ & $0.65(0.60 ; 0.68)$ & 2.22 & 0.03 & $1.05-4.71$ & 1,158 \\
\hline $\mathrm{LBN}$ & $8(6 ; 11)$ & $7(6 ; 8)$ & 0.35 & 0.00 & $0.17-0.73$ & 1,158 \\
\hline LBND & $0.67(0.58 ; 0.75)$ & $0.71(0.67 ; 0.83)$ & 4.05 & 0.00 & $1.53-13.53$ & 1,143 \\
\hline LDB & $85(63 ; 112)$ & $125(100 ; 164)$ & 6.80 & 0.00 & $2.57-22.71$ & 1,143 \\
\hline $\mathrm{AC}$ & $1,923(1,553 ; 2,339)$ & $1,485(1,163 ; 2,097)$ & 0.49 & 0.06 & $0.24-1.02$ & 1,167 \\
\hline $\mathrm{ACD}$ & $0.83(0.77 ; 0.88)$ & $0.82(0.76 ; 0.90)$ & 0.78 & 0.49 & $0.39-1.64$ & 1,154 \\
\hline
\end{tabular}
every parameter was scaled before model formulation,

Table 3. Median, first and third quartile, odds ratio (OR) for lameness, $P$-value, $95 \% \mathrm{CI}$, and number of animals of the analyzed parameters (n)

Median

(first; third quartile)

${ }^{1} \mathrm{CF}=$ change of feed; $\mathrm{S}=$ season; $\mathrm{P}=$ parity; $\mathrm{MY}=$ milk yield; $\mathrm{MI}=$ milking interval; $\mathrm{LW}=$ live weight; $\mathrm{FI}=$ feed intake; $\mathrm{FD}=$ feeding duration; FDD = feeding duration daytime; FP = feeding pace; $\mathrm{MN}=$ number of meals; MND = number of meals daytime; FDM = feeding duration per meal; FIM = feed intake per meal; VN = number of visits; VND = number of visits daytime; FDV = feeding duration per visit; FIV = feed intake per visit; LD = lying duration; LDD = lying duration daytime; LBN = number of lying bouts; LBND = number of lying bouts daytime; $\mathrm{LDB}=$ lying duration per bout; $\mathrm{AC}=$ activity; $\mathrm{ACD}=$ activity daytime 


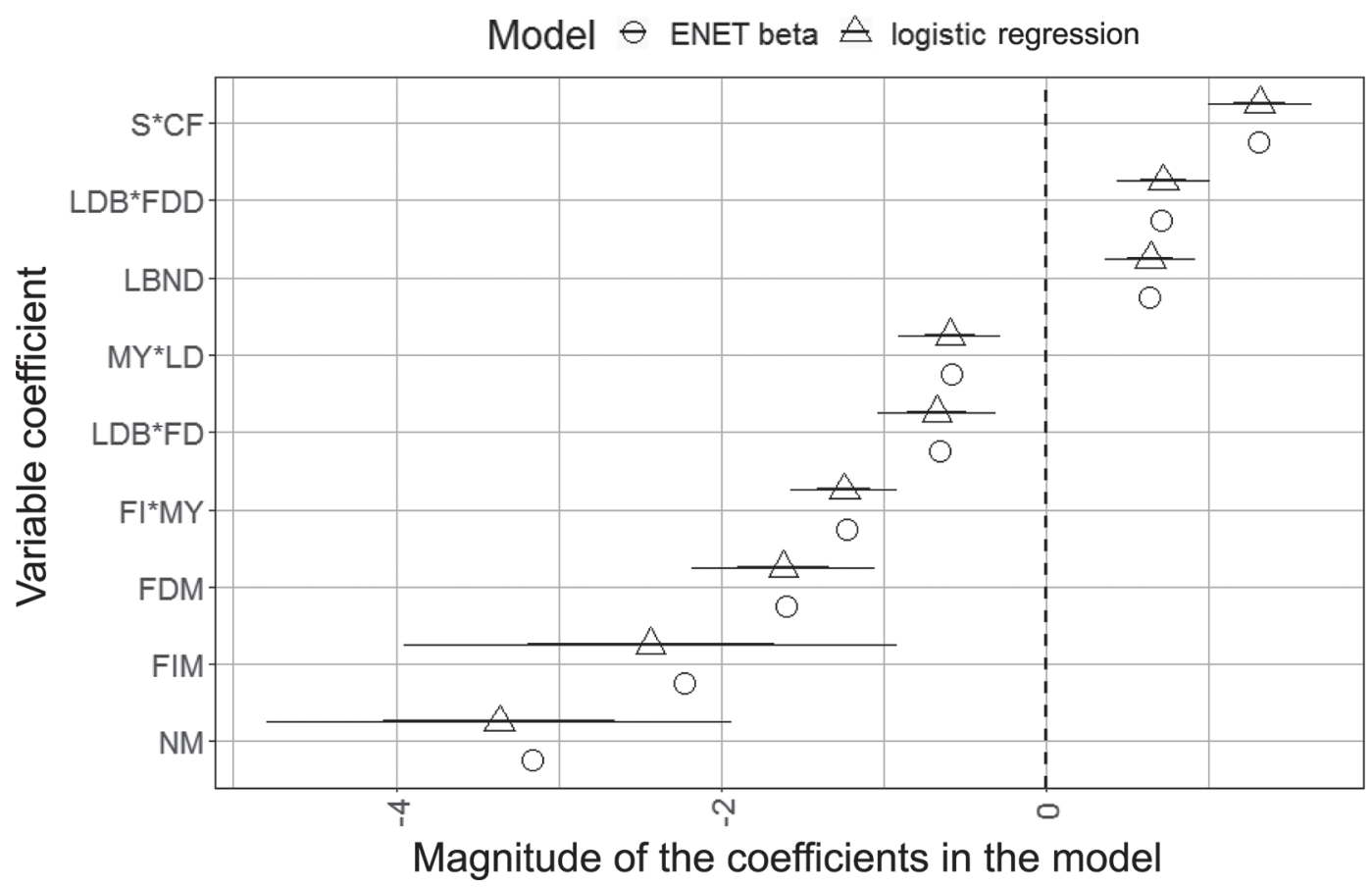

Figure 1. Comparison of the magnitude of the coefficients in the elastic net (ENET) beta model and in the logistic regression (it is not possible to calculate SE for an ENET). Darker lines represent the inner CI (1 SD), and lighter lines represent the outer CI (2 SD). LDB = lying duration per bout; FDD = feeding duration daytime; $\mathrm{MY}=$ milk yield; $\mathrm{LD}=$ lying duration; $\mathrm{FD}=$ feeding duration; $\mathrm{FI}=$ feed intake; $\mathrm{CF}=$ change of feed; $\mathrm{S}=$ season; LBND = number of lying bouts daytime; FDM = feeding duration per meal; FIM = feed intake per meal; NM = number of meals.

the coefficients in the model cannot be used to calculate odds ratios of the predictors, but the magnitude of the absolute values of the remaining parameters' coefficients can still be interpreted as their strength of association with the outcome. When ordered by magnitude, the coefficients all had the same rank as in the ENET beta model (Figure 1), indicating that the strength of association with lameness of the parameters in the ENET beta model is in the same order as in the logistic regression, too. The order of strength of association from greatest to least was as follows: MN, FIM, FDM, $\mathrm{S} \times \mathrm{CF}, \mathrm{FI} \times \mathrm{MY}, \mathrm{LDB} \times \mathrm{FDD}, \mathrm{LDB} \times$ $\mathrm{FD}, \mathrm{LBND}$, and $\mathrm{MY} \times \mathrm{LD}$. The predictors, which were part of an interaction term should not be interpreted separately, but only in their role as part of an interaction term, so they are left out of this enumeration. The direction of the association of the predictors with the outcome can also be deduced from the coefficients for a better understanding of the relationship between the predictors.

Single Predictors. The MN had a negative association with the outcome, meaning that the less cows tended to divide their time spent feeding into several meals, the more likely they were to be lame and vice versa: the more often cows went to feed, the less likely they were to be lame. The same accounts for FIM, so additionally, the smaller the amount of feed fed during one meal, the more likely a cow was to be lame. When FDM of a cow decreased, her probability for being lame increased. If a cow lay down more often during daytime, meaning that LBND increased, then she was also more likely to be lame.

Interaction Terms. The $\mathrm{S} \times \mathrm{CF}$ had the greatest importance of all of the interaction terms showing that the feeding trial had a significant influence on the lameness prediction. Effect plots were made for the rest of the interaction terms: FI $\times \mathrm{MY}, \mathrm{LDB} \times \mathrm{FDD}, \mathrm{LDB}$ $\times \mathrm{FD}$, and $\mathrm{MY} \times \mathrm{LD}($ Figures 2, 3, 4, and 5). Figure 2 shows the association between MY and lameness for 7 distinct values of FI from lowest to highest. When a cow fed more than average, the risk of being lame did not differ between lower or higher values of MY, but if she fed less than average, the risk of being lame increased with an increasing MY.

A similar effect could be observed for $\mathrm{MY} \times \mathrm{LD}$ (Figure 3). An increased MY was associated with an increased risk of lameness only in cows that lay down for less time per day than average. The risk of being lame was not affected by a higher MY in cows with longer than average LD per day.

The association between LDB and lameness was influenced by FD and as well as by FDD (Figures 4 


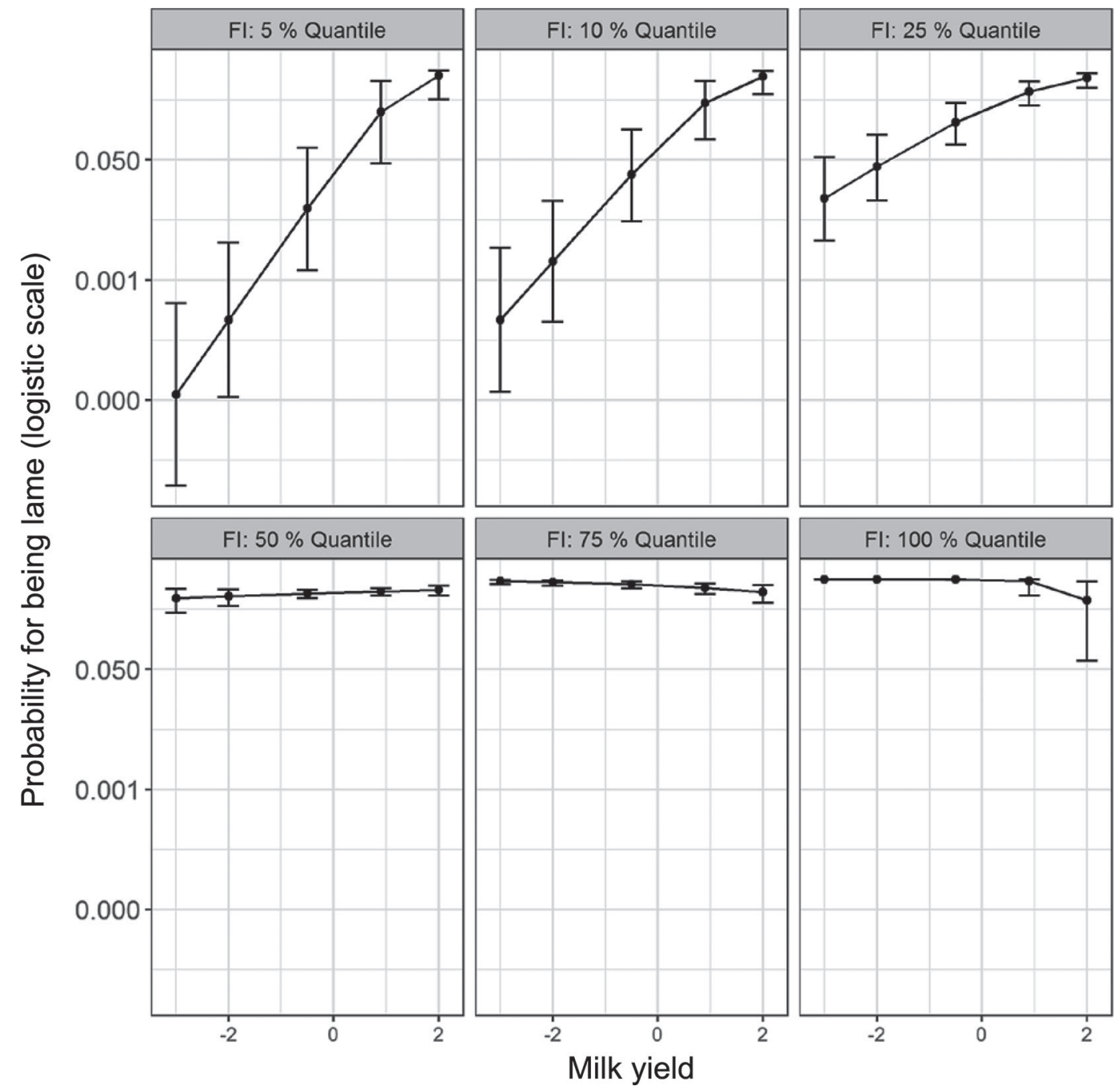

Figure 2. Effect plot of the interaction milk yield $\times$ feed intake (FI). Milk yield (kg): natural logarithm, centered, scaled; FI (kg): natural logarithm, centered, scaled. Error bars represent the $95 \%$ CI.

and 5). When cows spent less time feeding per $24 \mathrm{~h}$, they were more likely to be lame when LDB increased. If their FD was around average or higher, this effect could not be observed. As FDD, the time spent feeding during daytime as a percentage of the time spent feeding throughout the whole day, increased, meaning that cows fed primarily during daytime, then the risk of being lame increased with LDB. The more cows relatively fed at nighttime, the more this association diminished.

\section{DISCUSSION}

\section{Data Collection and Processing}

Reliability and Validity of the Reference Data. The modified LMS after Sprecher et al. (1997) was used as the gold standard for the lameness status. Animals were defined lame with an LMS $>3$, although in other similar publications animals scored 3 were already considered lame. But our stricter definition of animals showing "short-striding on one or more limbs" already being scored 4 instead of 3 provided easier, and thus to us, clearer differentiation. This was confirmed by the good value of Cohen's kappa of 0.7 (according to Landis and Koch, 1977) in the test for intra-rater variability. A more accurate reference will on the one hand result in a more accurate prediction model; on the other hand, a binary classification of lameness does not reflect the natural situation and therefore reduces the validity of the reference data. Several factors lead to a blurred line between the definition of lame and nonlame animals. First, cattle, being an animal of prey, try to avoid showing symptoms of a disease because it attracts predators' attention as this weakness suggests 


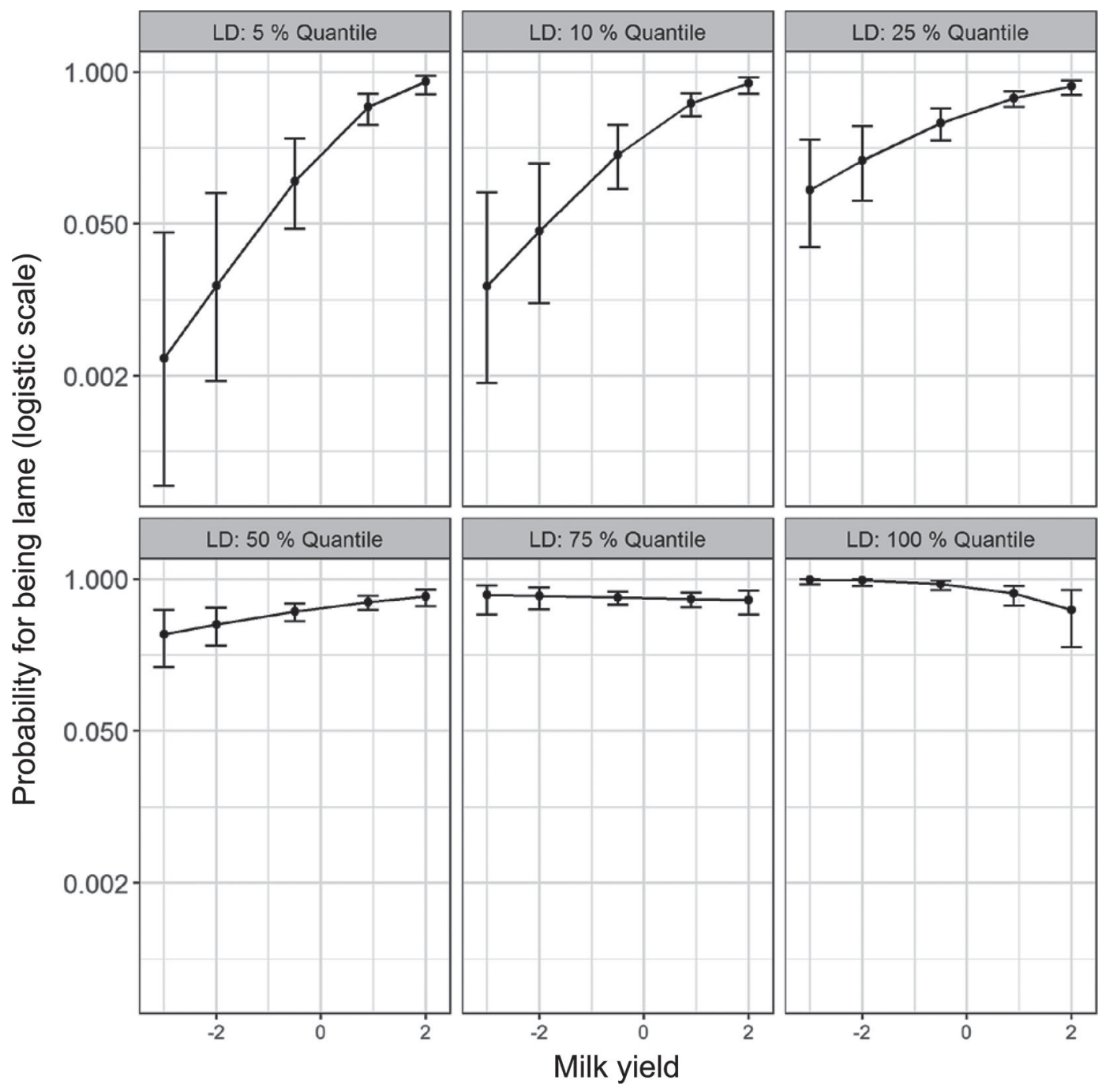

Figure 3. Effect plot of the interaction milk yield $\times$ lying duration $(\mathrm{LD})$. Milk yield $(\mathrm{kg})$ : natural logarithm, centered, scaled; LD (min): natural logarithm, centered, scaled. Error bars represent the $95 \%$ CI.

being easy prey. Therefore, cows could tend to hide lameness when a potential predator, such as a human observer, is present as is the case while locomotion scoring. Second, individuals show great variability in the actual reaction to experienced pain (Cutler et al., 2013; Raundal et al., 2014), meaning that the threshold of pain leading to visible lameness is also very individually different. Third, apart from pain causing lameness, other external factors such as udder size or quality of walking surface can influence locomotor behavior (Cook et al., 2004; Flower et al., 2006). Finally, a nondaily locomotion scoring could overestimate only intermittently occurring deviations in locomotor behavior.

These facts lead to the conclusion that no explicit distinction can be made between lame and nonlame, either by the reference system of locomotion scoring or by the analyzed model, and some uncertainty is inevitable when working with a binary classification for lameness in cattle. Trying to predict the 5 different scores instead of just 2 summarized groups would probably be more suitable, but the statistical method would be a lot more complex; thus, the results would be much more difficult to interpret.

Different Hoof Diseases. Most of the hoof diseases that had occurred during the study were claw horn disruptions rather than infectious diseases such as DD. It is possible that a different composition of disease incidence would have led to different changes in the analyzed parameters, which is why the results from this study should be verified in different populations. Additionally, different hoof diseases can have a different onset and temporal evolvement. Animals present- 
ing with gradually evolving diseases such as claw horn disruption as a consequence of mechanical overload will change their behavior rather slowly as opposed to animals suffering from an interdigital phlegmon (IP), which has a very prompt onset and thus will cause a more immediate change in behavior, too. Therefore, the optimal way data are analyzed would be different for acutely proceeding hoof diseases, where the change in behavior can be found when comparing the parameter values from before and after the day of onset of the disease within the same animal. In chronic or more slowly developing diseases, there might be no difference between 2 values observed in 2 , 3 , or even more consecutive days but only when going back further in time.
Daily Values. All of the sensor data were summarized to daily values. Only by using the daytime ratios the ultradian rhythm was taken into account. Fröhner (2011) could show that it can be highly influenced by the occurrence of disease. Garcia et al. (2014) used, between several other parameters, the variance of activity at a certain time of the day to determine lameness status in cows. Nikkhah (2011) showed that feeding behavior is substantially influenced by the time of day. Feed intake and feeding pace were significantly higher during the feeding at night in comparison to the feeding in the morning. Our results also show that the relation between daytime and nighttime behavior is highly relevant during the development of lameness in a cow. The use of shorter intervals of data summarization

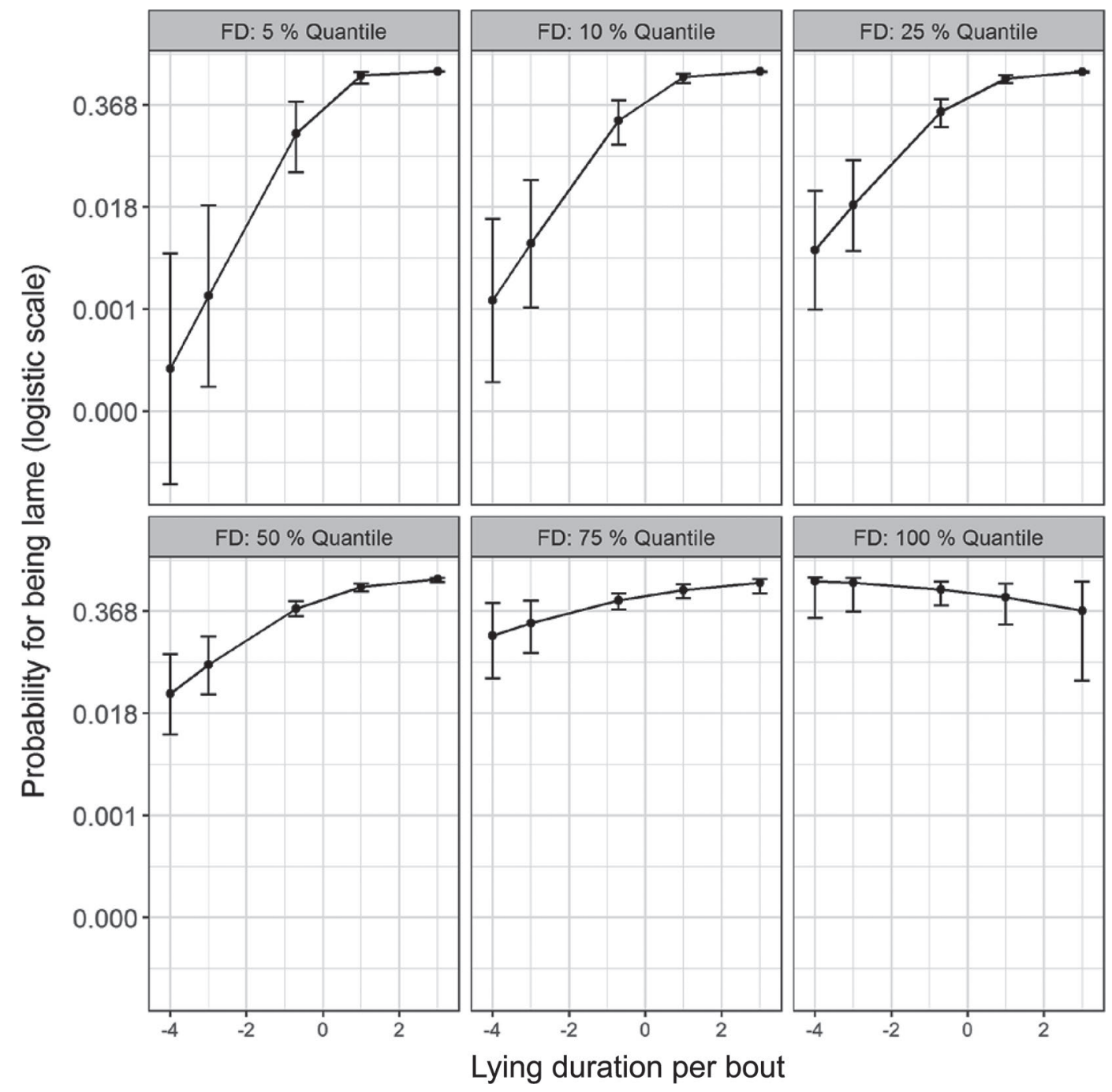

Figure 4. Effect plot of the interaction lying duration per bout $\times$ feeding duration (FD). Lying duration per bout (min): natural logarithm, centered, scaled; FD (min): natural logarithm, centered, scaled. Error bars represent the 95\% CI. 
could therefore result in higher prediction accuracy and should be looked at in more detail in future research.

\section{Accuracy of the Final Model}

Prediction accuracy of $0.83(0.78-0.88)$ for specificity and $0.92(0.88-0.96)$ for sensitivity of the presented model is one of the highest compared with similar studies with specificity and sensitivity of, respectively, 85 and $89 \%$ (Van Hertem et al., 2013), 82 and 72\% (Miekley et al., 2013), 76 and $73 \%$ (Kramer et al., 2009), 55 and $80 \%$ (Kamphuis et al., 2013), 77 and $79 \%$ in the first lactation and 83 and $79 \%$ in the second lactation (Garcia et al., 2014), and 89 and $86 \%$ (de Mol et al., 2013). Also, the number of animals in the trial was similar to most of these studies. Only Miekley et al.
(2013) and Kamphuis et al. (2013) analyzed the data of significantly more animals. However, none of the studies were conducted with Simmental cattle. All of the analyzed animals were dairy breeds such as Holstein or Danish Red. Additionally, only Garcia et al. (2014; with significantly lower prediction accuracy) and de Mol et al. (2013) used a systematic LMS as reference instead of only clinical documentation done by the farm staff, where most likely only the severe cases would be reported (Whay et al., 2002; Šárová et al., 2011). They separated between lame and nonlame cases between 2 and 3 of 4 grades for Garcia et al. (2014), treating only the rather severe cases as lame, and in contrast, between 2 and 3 of 5 cases for de Mol et al. (2013), considering already moderately lame cows as lame. However, both of the trials excluded cases with a score equal to 2 to

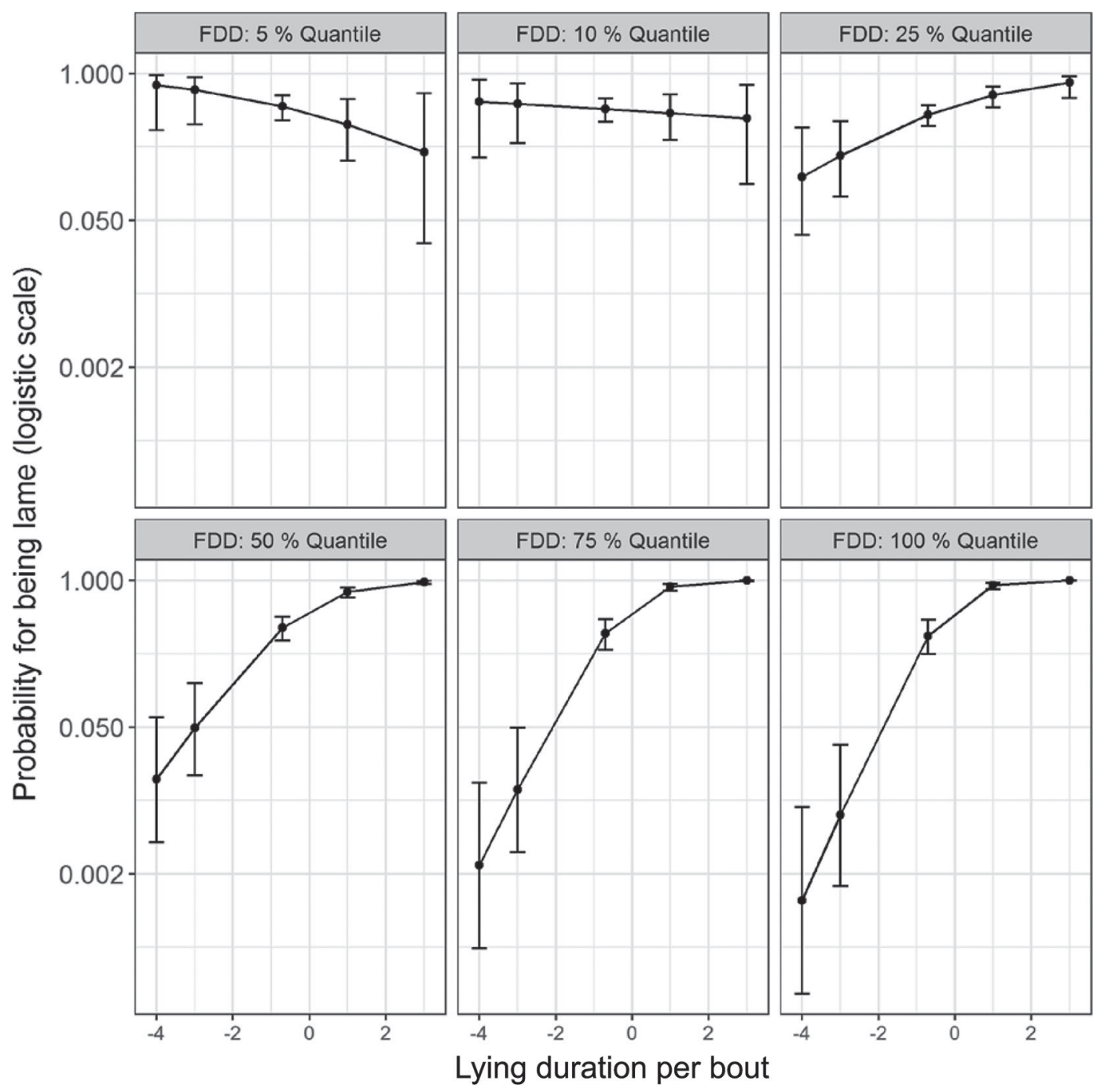

Figure 5. Effect plot of the interaction lying duration per bout $\times$ feeding duration daytime (FDD). Lying duration per bout (min): natural logarithm, centered, scaled; FDD: centered, scaled. Error bars represent the $95 \%$ CI. 
achieve a more distinct separation between lame and nonlame animals. Leaving out these more difficult to assign cases being on the verge of lameness is questionable because it can result in incorrectly high prediction accuracy.

\section{Analysis of the Predictors in the Model}

The analyzed parameters in the studies can roughly be categorized as follows: LW, MY, feed intake and feeding behavior, overall activity, and lying behavior. In our study parameter data of every group were collected, but neither LW nor overall activity contributed to the final model. Kamphuis et al. (2013) also investigated the effects of LW on lameness, as single predictor as well as in combination with milking order and activity, but did not find any relevant association in accordance with our study. Studies that only used overall activity in their calculations had lower prediction accuracy than those taking lying behavior into account as well, so lying behavior seems to have greater association with lameness. Activity is probably more influenced by other factors such as the behavior changes that are used for automatic heat detection (Kiddy, 1977).

Performance Parameters. The MY did not show any statistically significant association with lameness when used as a single predictor. In the more complex context with other behavioral and performance measures, it did contribute substantially to a better prediction accuracy. de Mol et al. (2013) and Kamphuis et al. (2013) also showed that in their models, MY had an effect on prediction accuracy for lameness, but Pavlenko et al. (2011) and Van Hertem et al. (2013) even excluded it from their models because it had no association with lameness in their data. Bach et al. (2007) found that lame cows did have a statistically significantly lower MY at the day of the lameness scoring than sound cows, but this was only the case in more severe cases of lameness with a LMS $>3$ according to Sprecher et al. (1997). The numerous studies that have been conducted only on the question if MY of the whole lactation is associated with lameness show very varying results. Green et al. (2002) showed that cows with a higher 305-d MY are at a higher risk of being lame at least once during the lactation. Hernandez et al. (2002) did not verify these results, but on the contrary, found that cows that had been lame during the lactation had a decreased MY compared with those that were nonlame throughout the whole lactation. This was only the case in animals having IP; in those presenting with lameness due to DD or claw horn disruption, no statistically significant association with 305-d MY was shown. Green et al. (2002) also found that MY did decrease after the onset of lameness. The same was found in the study of Warnick et al. (2001) in 1 of their 2 observed herds for animals with claw horn disruption more than for those with IP and DD. In the second herd, MY decreased lower after lameness had occurred in those cows being affected by IP rather than in those being affected by claw horn disruption or DD. In every one of the 3 studies, lameness was assessed only by clinical documentation done by the farm staff in contrast to systematic locomotion scoring. It is therefore possible that lameness was discovered in very different stages of the underlying disease, which could be one explanation for the variation in the results. We also assume that an important reason is the strong relationship of MY and FI as shown in our study. Only when FI was very low did an increased MY lead to a higher risk of being lame. If a cow fed an amount around average or higher, this effect could not be observed. That is why we conclude that an increased MY is indeed associated with a higher risk for lameness but only if the cow does not feed adequately compared with the amount of milk she produces. It is, therefore, highly important to provide enough feed in an adequate quality and easily accessible to every cow in the herd, in other words, to make it as easy as possible for cows to consume the required amount to avoid becoming lame.

Analogously, the risk of being lame increased with a higher MY only when cows lay down for less time. With an average or higher LD this effect disappeared, suggesting that the higher demand on the cow's metabolism could be compensated for by longer resting times when the organism could recuperate, and in particular, the skin and horn-forming tissue of the feet were released from the pressure load of the weight of the body.

Feeding and Lying Behavior. The most relevant factors being related to lameness status were the behavior parameters MN, FIM, and FDM. Apart from LBND, no lying-behavior-associated factor was relevant considered on its own, but only as part of the interaction terms $\mathrm{MY} \times \mathrm{LD}, \mathrm{LDB} \times \mathrm{FD}$, and $\mathrm{LDB} \times \mathrm{FDD}$. Lying and feeding behavior are influenced by many extrinsic factors, such as stocking density, feed bunk space, especially during the peak feeding period, cubicle and floor design, and so on (Cook et al., 2004, 2008; Gomez and Cook, 2010; Collings et al., 2011), as well as intrinsic factors such as time spent milking, DIM, parity, or other behaviors that take up time restricting the availability for the actual behavior (Arnold, 1984; Gomez and Cook, 2010; Westin et al., 2016). Feeding and lying behavior could therefore be less useful in the specific prediction of certain disease symptoms such as lameness. However, the strong relationship between these 2 behavioral complexes proved to have great potential for lameness monitoring in our study. 
Generally, since feeding occurs while standing when the cow bears her whole weight on her feet, a lame cow will try to reduce feeding and thereby standing time. At least in sound grazing cows, Arnold (1984) found that lying duration is highly negatively correlated with feeding duration; lying duration therefore is likely to increase when feeding duration decreases. A hindrance to increasing lying time, however, is the fact that the unbalanced weight bearing and therefore increased weight load on one foot at a time during the process of lying down (or standing up) can increase the pressure-induced pain caused by a hoof lesion. So, if cows present with a hoof lesion, especially on less deformable stall bases such as rubber as opposed to well-maintained sand or deep straw bedding, they avoid standing up and lying down (Gomez and Cook, 2010).

In our study we found an increased LDB as an indicator of lameness, which is in line with the former stated hypotheses: an increased lying duration combined with less standing up and lying down in lame cows must lead to a prolonged LDB. However, it is very interesting that this effect was only present when at the same time FD was decreased or FDD was increased; thus, the effect is not consistent. Then again, this fact can explain the differing results of other studies that did not look into the interactions between feeding and lying behavior showing that LDB either did not change significantly (Gomez and Cook, 2010) or increase (Ito et al., 2010; Westin et al., 2016), and some studies that found an increase (Calderon and Cook, 2011), a decrease (Westin et al., 2016), or no change (Yunta et al., 2012) of the LBN in lame cows. On the contrary, the effect of FD on lameness status is very consistent in the literature; lame cows feed shorter times than sound cows (Norring et al., 2014; Thorup et al., 2016). In our final model, this effect was significantly influenced by LDB. The same accounts for FDD, which we could not find results for in any other similar study about the associations between lameness and feeding behavior. In summary, this suggests that a change in either LDB and FD or rather FDD can be part of physiological behavior to adapt to occurring intrinsic or extrinsic factors, and only if both LDB and FD or FDD show a change in the critical direction, a cow is very likely to present with lameness.

The increase of FDD in lame cows, in other words, the tendency to spend available time at night for resting rather than for feeding (Overton et al., 2002), was more prominent in lame than in sound cows, presumably to avoid standing and the painful process of standing up, and explains the increased LBND in lame cows in this study, too. The more lying bouts a cow had during daytime relative to the whole day, the more likely she was to be lame. In comparison, sound cows had relatively more lying bouts during the nighttime than during the day. The increased LBND in lame cows could have been the result of either a relatively decreased LBN on the whole day, a relatively increased LBN at daytime, or both. Both scenarios are in fact plausible: Night is the time cows rest most and feed less (Arnold, 1984; Overton et al., 2002). Accordingly, in the daytime, lying is more likely to be interrupted by a feeding event than at night and a cow will be able to reduce the number of lying bouts by reducing feeding events to the minimum more easily at nighttime. Presumably, lame cows also lay down more often between 2 feeding events rather than standing or walking around like sound cows would. In fact, Yunta et al. (2012) showed that on average lame cows got up 13 min later after feed was distributed in the feed bunk and lay down again 19 min earlier than sound cows did. Lying behavior data in our study did not have a time stamp but were provided in minutes per daily hour by the pedometer system. That is why we were not able to look into the temporal dependency of lying and feeding behavior in more detail, but according to our results, we think that in future research it would be interesting to investigate the behavior of lame cows during the interval between 2 feeding events.

In contrast to FD and FDD, the meal criterion-related feeding parameters MN, FIM, and FDM contributed to the model on their own. Lame cows fed in fewer and shorter meals with a decreased intake per meal. This suggests an also decreased FI in lame cows, but as shown this was only true for high-yielding cows. The reduced duration and number of meals is again explained by the fact that feeding occurs while standing and standing up as well as standing itself is painful when a cow presents with a hoof lesion. Taking less time per meal, FIM was consequently reduced too, so cows did not compensate for shorter FDM with a higher feeding pace. These findings are in accordance with those of the study conducted by Bach et al. (2007).

\section{Practical Relevance}

To apply the knowledge about the association between the investigated parameters and lameness on farm, sensors to measure MY as well as lying and feeding behavior are needed. Milk meters are becoming more common in modern milking systems and more and more farms make use of automatic activity sensors like the pedometers used in our study for heat detection and general health monitoring. In the trial, weighing troughs, which are very costly and therefore not suitable for practical application, were used to collect feeding behavior data, but for instance the Track a Cow pedometers we used to measure lying behavior can now be combined with an induction loop that can be easily 
installed at the feeding alley so that an animal is identified when its pedometer enters the magnetic field. This way, measurement of feeding behavior can be done with the same system that measures lying behavior and is also already used for heat detection. The installation of additional technical equipment would not be required. Therefore, we think that automatic lameness detection could be practicable with an adequate amount of economic effort in modern dairy farms in the near future.

\section{CONCLUSIONS}

Automatically measurable behavior and performance data can be used to detect lameness. In doing so, it is important to consider the complex interactions between performance, feeding, and lying behavior. This study has contributed to a deeper understanding of these. The very good performance of the model in our study compared with similar work suggests that the inclusion of associations between the independent variables is a way to increase prediction accuracy in automatic lameness detection.

\section{ACKNOWLEDGMENTS}

We thank the farm staff for taking care of our study cows and helping gather the data during locomotion scoring and treatment of the animals as well as ENGS Systems (Rosh Pina, Israel) for their support in data processing and for providing us with their system. We thank the Bavarian State Ministry of Food, Agriculture and Forestry for funding this study.

\section{REFERENCES}

Arnold, G. W. 1984. Comparison of the time budgets and circadian patterns of maintenance activities in sheep, cattle and horses grouped together. Appl. Anim. Behav. Sci. 13:19-30. https://doi .org/10.1016/0168-1591(84)90048-0.

Bach, A., M. Dinarés, M. Devant, and X. Carré. 2007. Associations between lameness and production, feeding and milking attendance of Holstein cows milked with an automatic milking system. J. Dairy Res. 74:40-46.

Barker, Z. E., K. A. Leach, H. R. Whay, N. J. Bell, and D. C. J. Main. 2010. Assessment of lameness prevalence and associated risk factors in dairy herds in England and Wales. J. Dairy Sci. 93:932-941.

Blackie, N., J. Amory, E. Bleach, and J. Scaife. 2011. The effect of lameness on lying behaviour of zero grazed Holstein dairy cattle. Appl. Anim. Behav. Sci. 134:85-91.

Brade, W., H. Hamann, E. Brade, and O. Distl. 2008. Untersuchungen zum Verlustgeschehen von Erstkalbinnen in Sachsen. Zuchtungskunde 80:127-136.

Calderon, D. F., and N. B. Cook. 2011. The effect of lameness on the resting behavior and metabolic status of dairy cattle during the transition period in a freestall-housed dairy herd. J. Dairy Sci. 94:2883-2894.

Chawla, N. V., K. W. Bowyer, L. O. Hall, and W. P. Kegelmeyer. 2002. SMOTE: Synthetic Minority Over-sampling Technique. J. Artif. Intell. Res. 16:321-357.
Cohen, J. 1960. A coefficient of agreement for nominal scales. Educ. Psychol. Meas. 20:37-46.

Collings, L. K. M., D. M. Weary, N. Chapinal, and M. G. von Keyserlingk. 2011. Temporal feed restriction and overstocking increase competition for feed by dairy cattle. J. Dairy Sci. 94:5480-5486. https://doi.org/10.3168/jds.2011-4370.

Cook, N. B., T. B. Bennett, and K. V. Nordlund. 2004. Effect of free stall surface on daily activity patterns in dairy cows with relevance to lameness prevalence. J. Dairy Sci. 87:2912-2922.

Cook, N. B., M. J. Marin, R. L. Mentink, T. B. Bennett, and M. J. Schaefer. 2008. Comfort zone-design free stalls: Do they influence the stall use behavior of lame cows? J. Dairy Sci. 91:4673-4678.

de Mol, R. M., G. Andre, E. J. Bleumer, J. T. van der Werf, Y. de Haas, and C. G. van Reenen. 2013. Applicability of day-to-day variation in behavior for the automated detection of lameness in dairy cows. J. Dairy Sci. 96:3703-3712.

Dippel, S., M. Dolezal, C. Brenninkmeyer, J. Brinkmann, S. March, U. Knierim, and C. Winckler. 2009. Risk factors for lameness in freestall-housed dairy cows across two breeds, farming systems, and countries. J. Dairy Sci. 92:5476-5486.

Flower, F. C., D. J. Sanderson, and D. M. Weary. 2006. Effects of milking on dairy cow gait. J. Dairy Sci. 89:2084-2089.

Fröhlich, G., S. Böck, G. Rödel, F. Wendling, and G. Wendl. 2005 Automatische Fütterungsanlagen für Versuchs- und Prüfbetriebe. Landtechnik 60:102-103.

Fröhner, A. 2011. Lokomotion, Ruheverhalten und Gesundheitsstatus von Kälbern in den Haltungssystemen Rein-Raus und kontinuierliche Belegung bei Eimer- und Automatentränke im neuen Außenklimastall. Diss. Tech. Univ. Münch.

Garcia, E., I. Klaas, J. M. Amigo, R. Bro, and C. Enevoldsen. 2014. Lameness detection challenges in automated milking systems addressed with partial least squares discriminant analysis. J. Dairy Sci. 97:7476-7486.

Gomez, A., and N. B. Cook. 2010. Time budgets of lactating dairy cattle in commercial freestall herds. J. Dairy Sci. 93:5772-5781. https://doi.org/10.3168/jds.2010-3436.

Green, L. E., V. J. Hedges, Y. H. Schukken, R. W. Blowey, and A. J. Packington. 2002. The impact of clinical lameness on the milk yield of dairy cows. J. Dairy Sci. 85:2250-2256.

Hernandez, J., J. K. Shearer, and D. W. Webb. 2002. Effect of lameness on milk yield in dairy cows. J. Am. Vet. Med. Assoc. 220:640-644.

Cutler, J. H., G. Cramer, J. J. Walter, S. T. Millman, and D. F. Kelton. 2013. Randomized clinical trial of tetracycline hydrochloride bandage and paste treatments for resolution of lesions and pain associated with digital dermatitis in dairy cattle. J. Dairy Sci. 96:7550-7557.

Hoerl, A., and W. Kennard. 1970. Ridge regression: Biased estimation for nonorthoganal problems. Technometrics 12:55-67.

Ito, K., M. A. G. von Keyserlingk, S. J. Leblanc, and D. M. Weary. 2010. Lying behavior as an indicator of lameness in dairy cows. J. Dairy Sci. 93:3553-3560.

Kamphuis, C., E. Frank, J. K. Burke, G. A. Verkerk, and J. G. Jago. 2013. Applying additive logistic regression to data derived from sensors monitoring behavioral and physiological characteristics of dairy cows to detect lameness. J. Dairy Sci. 96:7043-7053.

Kiddy, C. A. 1977. Variation in physical activity as an indication of estrus in dairy cows. J. Dairy Sci. 60:235-243. https://doi.org/10 .3168/jds.S0022-0302(77)83859-9.

Kramer, E., D. Cavero, E. Stamer, and J. Krieter. 2009. Mastitis and lameness detection in dairy cows by application of fuzzy logic. Livest. Sci. 125:92-96.

Landeskuratorium der Erzeugerringe für tierische Veredelung in Bayern e. V. 2015. Leistungs- und Qualitätsprüfung in der Rinderzucht in Bayern 2014, Ergebnisse und Auswertungen. LKV Bayern, Munich, Germany.

Landis, J. R., and G. G. Koch. 1977. The measurement of observer agreement for categorical data. Biometrics 33:159.

Laven, R. A., K. E. Lawrence, J. F. Weston, K. R. Dowson, and K. J. Stafford. 2008. Assessment of the duration of the pain response associated with lameness in dairy cows, and the influence of treatment. N. Z. Vet. J. 56:210-217. 
Leach, K. A., D. A. Tisdall, N. J. Bell, D. C. J. Main, and L. E. Green. 2012. The effects of early treatment for hindlimb lameness in dairy cows on four commercial UK farms. Vet. J. 193:626-632.

Liu, W., and Q. Li. 2017. An efficient elastic net with regression coefficients method for variable selection of spectrum data. PLoS One 12:e0171122. https://doi.org/10.1371/journal.pone.0171122.

Miekley, B., E. Stamer, I. Traulsen, and J. Krieter. 2013. Implementation of multivariate cumulative sum control charts in mastitis and lameness monitoring. J. Dairy Sci. 96:5723-5733.

Miguel-Pacheco, G. G., J. Kaler, J. Remnant, L. Cheyne, C. Abbott, A. P. French, T. P. Pridmore, and J. N. Huxley. 2014. Behavioural changes in dairy cows with lameness in an automatic milking system. Appl. Anim. Behav. Sci. 150:1-8.

Nikkhah, A. 2011. Bioscience of ruminant intake evolution: Feeding time models. Adv. Biosci. Biotechnol. 2:1-4.

Norring, M., J. Haggman, H. Simojoki, P. Tamminen, C. Winckler, and M. Pastell. 2014. Short communication: Lameness impairs feeding behavior of dairy cows. J. Dairy Sci. 97:4317-4321.

Oberschätzl-Kopp, R. 2018. Verhalten von Milchkühen bei statischen und dynamischen Fütterungskonzepten in automatisierten Stallsystemen. Technische Universität München, München.

Overton, M. W., W. M. Sischo, G. D. Temple, and D. A. Moore. 2002. Using time-lapse video photography to assess dairy cattle lying behavior in a free-stall barn. J. Dairy Sci. 85:2407-2413. https:// doi.org/10.3168/jds.S0022-0302(02)74323-3.

Ozswari, L., R. Barna, and L. Visnyei. 2007. Economic losses due to bovine foot diseases in large-scale Holstein-Friesian dairy herds. Magy. Állatorv. Lapja 129:23-28.

Pavlenko, A., C. Bergsten, I. Ekesbo, T. Kaart, A. Aland, and L. Lidfors. 2011. Influence of digital dermatitis and sole ulcer on dairy cow behaviour and milk production. Animal 5:1259-1269.

R Core Team. 2015. R: A Language and Environment for Statistical Computing. R Foundation for Statistical Computing, Vienna, Austria.

Rademacher, G., A. Friedrich, T. Eberhardt, and W. Klee. 2004. Möglichkeiten zur Verbesserung der Tiergesundheit, des Tierschutzes und der Wirtschaftlichkeit in der Rinderhaltung Teil 1. Tierarztl. Umsch. 59:195-202.

Raundal, P. M., P. H. Andersen, N. Toft, B. Forkman, L. Munksgaard, and M. S. Herskin. 2014. Handheld mechanical nociceptive threshold testing in dairy cows - intra-individual variation, interobserver agreement and variation over time. Vet. Anaesth. Analg. 41:660-669.

Šárová, R., I. Stehulová, P. Kratinová, P. Firla, and M. Spinka. 2011. Farm managers underestimate lameness prevalence in Czech dairy herds. Anim. Welf. 20:201-204.

Souza, R. C., P. M. Ferreira, L. R. Molina, A. V. Carvalho, and E. J. Facury-Filho. 2006. Economic losses caused by sequels of lameness in free-stall housed dairy cows. Arq. Bras. Med. Vet. Zootec. 58:982-987.

Sprecher, D. J., D. E. Hostetler, and J. B. Kaneene. 1997. A lameness scoring system that uses posture and gait to predict dairy cattle reproductive performance. Theriogenology 47:1179-1187.
Thorup, V. M., L. Munksgaard, P.-E. Robert, H. W. Erhard, P. T Thomsen, and N. C. Friggens. 2015. Lameness detection via legmounted accelerometers on dairy cows on four commercial farms. Animal 9:1704-1712.

Thorup, V. M., B. L. Nielsen, P.-E. Robert, S. Giger-Reverdin, J Konka, C. Michie, and N. C. Friggens. 2016. Lameness affects cow feeding but not rumination behavior as characterized from sensor data. Front. Vet. Sci. 3. https://doi.org/10.3389/fvets.2016.00037.

Tibshirani, R. 1996. Regression shrinkage and selection via the lasso J. R. Stat. Soc. Ser. B Methodol. 58:267-288.

Tolkamp, B. J., D. P. Schweitzer, and I. Kyriazakis. 2000. The biologically relevant unit for the analysis of short-term feeding behavior of dairy cows. J. Dairy Sci. 83:2057-2068. https://doi.org/10 .3168/jds.S0022-0302(00)75087-9.

Van Hertem, T., C. Bahr, A. Schlageter Tello, S. Viazzi, M. Steensels, C. E. B. Romanini, C. Lokhorst, E. Maltz, I. Halachmi, and D. Berckmans. 2016. Lameness detection in dairy cattle: Single predictor v. multivariate analysis of image-based posture processing and behaviour and performance sensing. Animal 10:1525-1532.

Van Hertem, T. E. Maltz, A. Antler, C. E. B. Romanini, S. Viazzi, C. Bahr, A. Schlageter-Tello, C. Lokhorst, D. Berckmans, and I. Halachmi. 2013. Lameness detection based on multivariate continuous sensing of milk yield, rumination, and neck activity. J. Dairy Sci. 96:4286-4298.

von Keyserlingk, M. A. G., A. Barrientos, K. Ito, E. Galo, and D. M. Weary. 2012. Benchmarking cow comfort on North American freestall dairies: Lameness, leg injuries, lying time, facility design, and management for high-producing Holstein dairy cows. J. Dairy Sci. 95:7399-7408.

Warnick, L. D., D. Janssen, C. L. Guard, and Y. T. Grohn. 2001. The effect of lameness on milk production in dairy cows. J. Dairy Sci. 84:1988-1997.

Westin, R., A. Vaughan, A. M. de Passille, T. J. DeVries, E. A. Pajor, D. Pellerin, J. M. Siegford, E. Vasseur, and J. Rushen. 2016. Lying times of lactating cows on dairy farms with automatic milking systems and the relation to lameness, leg lesions, and body condition score. J. Dairy Sci. 99:551-561.

Whay, H. R., D. C. J. Main, L. E. Green, and A. J. F. Webster. 2002 Farmer perception of lameness prevalence. Pages 355-358 in Proc. 12th Int. Symp. Lameness Rumin. J. K. Shearer, Cornell University, Ithaca, NY.

Yeates, M. P., B. J. Tolkamp, D. J. Allcroft, and I. Kyriazakis. 2001 The use of mixed distribution models to determine bout criteria for analysis of animal behaviour. J. Theor. Biol. 213:413-425. https://doi.org/10.1006/jtbi.2001.2425.

Yeates, M. P., B. J. Tolkamp, and I. Kyriazakis. 2002. The relationship between meal composition and long-term diet choice. J. Anim. Sci. 80:3165-3178. https://doi.org/10.2527/2002.80123165x.

Yunta, C., I. Guasch, and A. Bach. 2012. Short communication: Lying behavior of lactating dairy cows is influenced by lameness especially around feeding time. J. Dairy Sci. 95:6546-6549.

Zou, H., and T. Hastie. 2005. Regularization and variable selection via the elastic net. J. R. Stat. Soc. B 67:301-320. 